\title{
PERENCANAAN JARINGAN LTE DENGAN MEMANFAATKAN LAMPU PENERANGAN JALAN SEBAGAI TITIK BASE STATION DI WILAYAH DENPASAR
}

\author{
Aprilindo Purba1, Pande Ketut Sudiarta, I G.A.K Diafari Djuni Hartawan ${ }^{3}$. \\ ${ }^{1,2,3}$ Program Studi Teknik Elektro, Fakultas Teknik Universitas Udayana \\ Email: aprilindoparkahap@gmail.com ${ }^{1}$, sudiarta@unud.ac.id $^{2}{ }^{2}$ igakdiafari@unud.ac.id $^{3}$
}

\begin{abstract}
Abstrak
Perkembangan teknologi seluler LTE dengan kecepatan data yang tinggi mengakibatkan cakupan BTS menjadi lebih kecil. Akibatnya jumlah BTS yang dibutuhkan bertambah dan ketinggiannya menurun. Kebutuhan BTS dalam penelitian ini memanfaatkan LPJ di kota Denpasar. Jumlah LPJ sebanyak 16.685 titik dengan ketinggian 11meter hingga 23meter. Dengan memanfaatkan 16.685 titik LPJ pada penelitian ini, maka dapat mencakupi layanan LTE di wilayah Denpasar. Metode yang digunakan dalam penelitian yaitu mengumpulkan data dan gambaran LPJ, melakukan desain BTS pada lampu penerangan jalan, melakukan perhitungan dengan menggunakan model propagasi Cost-231 dan simulasi dengan menggunakan software Atoll, menghapus beberapa titik apabila terjadi overlapping coverage, melakukan tilt antena apabila terjadi blankspot. Sehingga hasil simulasi dari jumlah LPJ yang digunakan untuk mencakupi seluruh wilayah Denpasar yaitu 30 titik yang terdiri dari 5 site dengan tinggi antena 23meter, 4 site dengan tinggi antena 15meter, 2 site dengan tinggi antena 13meter, dan 21 site dengan tinggi antena 11 meter.
\end{abstract}

kata kunci: Base Station, Blankspot, Coverage Area, Lampu Penerangan Jalan.

\section{PENDAHULUAN}

Meningkatnya kondisi kebutuhan membuat permintaan layanan komunikasi mengalami peningkatan. Komunikasi dengan laju tinggi, kapasitas yang besar, dan mobilitas yang tinggi merupakan tuntutan lebih kanjut yang diinginkan oleh pelanggan. Sedangkan dari segi penyedia jaringan diperlukan desain jaringan sederhana namun dapat bekerja seoptimal mungkin [1].

Pemenuhan kebutuhan akan cakupan layanan merupakan salah satu hal yang menjadi pertimbangan desain agar dapat memenuhi kebutuhan tersebut. Untuk itu memenuhi cakupan dengan cepat, maka salah satu caranya adalah memanfaatkan infrastruktur yang telah ada. Berdasarkan hal itu, maka tiang lampu penerangan jalan dapat dimanfaatkan. Sehingga pada penelitian ini dilakukan desain penempatan base station pada lampu penerangan jalan. Hal yang dilakukan adalah melakukan perhitungan dan simulasi pada ketinggian lampu penerangan jalan yang berbeda. melakukan simulasi pada seluruh wilayah kota Denpasar dengan meng-gunakan titik koordinat lampu penerangan jalan, melakukan tilt antena apabila terdapat wilayah blankspot.

Penelitian perencanaan jaringan Long

Term Evaluation (LTE) dengan memanfaatkan lampu penerangan jalan dilakukan karena terdapat beberapa wilayah tidak tercakupi layanan LTE. Dengan menggunakan lampu penerangan jalan sebagai titik base station maka mencakupi layanan LTE seluruh Denpasar dikarenakan jumlah titik lampu penerangan jalan sangat banyak di wilayah Denpasar dan juga dari pihak provider dapat mempermudah penentuan lahan dan perijinan lampu penerangan sebagai titik base station.

Penelitian ini juga bertujuan untuk mengetahui jumlah lampu penerangan jalan dengan tinggi yang berbeda yang digunakan 
sebagai solusi penempatan base station di wilayah Denpasar.

Penelitian ini dibuat mengacu pada mengembangkan penelitian yang pernah dilakukan mengenai perencanaan jaringan LTE [2]. Dalam penelitian tersebut dilakukan perhitungan dan simulasi jarak jangkauan antena dan simulasi pengaruh tilt antena terhadap jarak jangkauan antena. Pengembangan yang dilakukan adalah simulasi menggunakan software Atoll dengan mengambil topik penelitian sebelumnya, yaitu perhitungan dan simulasi jarak jangkauan antena dan tilt antena. Hasil perbandingan yang dilakukan digunakan untuk melakukan simulasi perencanaan jaringan LTE pada wilayah Denpasar.

\section{KAJIAN PUSTAKA}

Tinjauan Pustaka pada penelitian ini mengacu kepada beberapa literatur yang terkait dengan penelitian yang dilakukan. Teori yang diambil berupa Long Term Evolution, MAPL, model propagasi, tilting antena, dan lampu penerangan jalan.

\subsection{Long Term Evolution (LTE)}

Long Term Evolution (LTE) adalah jaringan akses radio evolusi jangka panjang keluaran dari $3^{\text {rd }}$ Generation Patnership Project (3GPP). LTE merupakan kelanjutan dari teknologi generasi ketiga (3G). LTE diperkenalkan dalam satu rangkaian dengan System Architecture Evolution (SAE) sebagai inti dari jaringan generasi keempat menurut standar 3GPP [3].

Gambar 1 merupakan arsitektur jaringan LTE. Data dipertukarkan antara User Equipment (UE) dan Evolved NodeB (eNB). Stasiun induk melalui antar muka udara. eNB adalah bagian E-UTRAN, yaitu semua fungsi dan jaringan servis disetarakan.

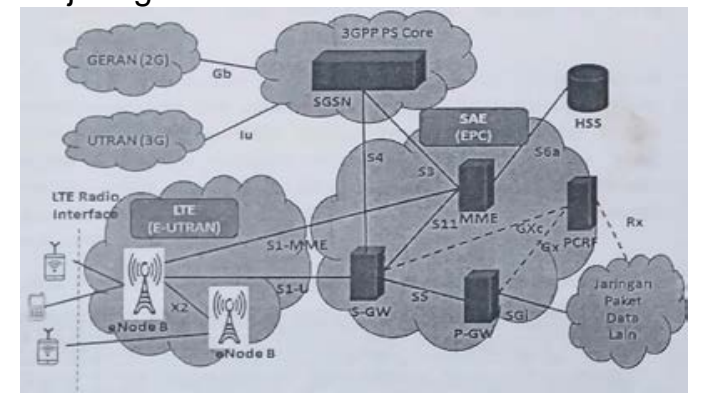

Gambar 1 Arsitektur jaringan LTE.

Arsitektur LTE terdiri atas dua bagian utama yakni LTE itu sendiri yang dikenal juga sebagai E-UTRAN dan Bagian Sentral (SAE) yang merupakan jantung dari sistem LTE yang dikenal juga sebagai EPC. Berikut ini adalah penjelasan masing-masing bagian dari arsitektur LTE:

1. Bagian akses radio (LTE)

- User equitment (UE): UE adalah perangkat komunikasi pengguna. Perangkat ini dapat berupa telepon genggam, tablet, computer, maupun segala perangkat cerdas yang dapat terhubung dengan internet.

- Evolved NodeB (eNB): eNB adalah antar muka jaringan LTE dengan pengguna perangkat komunikasi. Pada jaringan GSM dikenal sebagai BTS dan pada jaringan UMTS dikenal sebagai Node B. perbedaan eNB dengan BTS maupun Node B adalah kemampuanya untuk melakukan fungsi control sambungan dan Handover. Dengan demikian tidak ada lagi pengatur tambahan seperti BSC atau RNC pada sistem LTE

2. Bagian sentral (SAE):

- Mobility Management Entity (MME) : MME merupakan elemen control utama yang terdapat pada EPC. Biasanya pelayanan MME pada lokasi keamanan operator. Pengoperasiannya hanya pada control plane dan tidak meliputi data user plane. Fungsi utama MME pada arsitektur jaringan LTE adalah sebagai authentication dan security, mobility management, managing subscription profile dan service connectivity.

- Serving Gateway (S-GW) : Pada arsitektur jaringan LTE, level fungsi tertinggi S-GW adalah jembatan antara manajemen dan switching user plane. S-GW merupakan bagian dari infrastruktur jaringan sebagai pusat operasional dan maintenance. Peranan S-GW sangat sedikit pada fungsi pengontrolan. Hanya bertanggung jawab pada sumbernya sendiri dan mengalokasikannya berdasarkan permintaan MME, P-GW, atau PCRF, yang memerlukan set-up, modifikasi atau penjelasan pada UE. 
- P-GW/ gateway PDN : PDN- gateway adalah komponen penting pada LTE untuk melakukan terminasi dengan paket data network (PDN). P-GW bertugas untuk mengatur hubungan jaringan data antara UE dengan jaringan paket data lain di luar 3 GPP seperti WLAN, Wimax, CDMA 2000, dan EVDO.

- Policy and charging rules function (PCRF): PCRF merupakan bagian dari arsitektur jaringan yang mengumpulkan informasi dari jaringan, sistem pendukung operasional, dan sumber lainya seperti portal secara real time, yang mendukung pembentukan aturan dan kemudian secara otomatis membuat kebijakan untuk setiap pelanggan aktif di jaringan. PCRF berfungsi untuk menentukan Quality of Service (QoS) dan charging untuk masingmasing LTE.

- Home Subcriber Server (HSS): HSS merupakan sistem database yang bertugas untuk membantu MME dalam melakukan manajemen pelanggan dan pengamanan. Penerimaan atau penolakan UE saat autentikasi bergantung pada data HSS.[2].

\subsection{Maximum Allowable Path Loss (MAPL)}

Maximum Allowable Path Loss merupakan nilai maksimum dari nilai propagasi antara perhitungan nilai dari perangkat eNodeB dan mobile station, dengan nilai perhitungan MAPL ini dibagi menjadi dua, yaitu arah MAPL uplink dan downlink. Nilai uplink digunakan untuk menentukan nilai maksimum redaman propagasi dari mobile station ke eNodeB, dan nilai downlink. Maximum Allowable Path Loss merupakan nilai redaman maksimum propagasi dari eNodeB ke mobile station agar tetap dapat melayani keperluan dari komunikasi untuk seluruh user dalam suatu cakupan daerah.

\subsection{Model Propagasi Cost-231 Hatta}

Redaman propagasi pada transmisi radio antara MS dan BTS dapat berpengaruh terhadap besarnya cakupan yang dapat dilayani BTS. Model propagasi Cost 231 Hatta digunakan untuk mengetahui radius sel pada Personal Communication System (PCS) pada wilayah urban density yang dalam hal ini digunakan pada frekuensi dengan range frekuensi 1500-2000 MHz.

Persamaan yang digunakan untuk menghitung propagasi yang terjadi $\mathrm{di}$ daerah urban adalah sebagai berikut.

$L u=46.3+33.9 \log f_{c}-13.82 \log h_{m}-a$ $\left(h_{m}\right)+\left(44.9-6.55 \log h_{b}\right) \log d+$

$\mathrm{C}_{\mathrm{m} \ldots . . .}(1)$

$C_{M}\left\{\begin{array}{cr}0 \mathrm{~dB} & \text { for medium sized city and urban areas } \\ 3 \mathrm{~dB} & \text { for metropolitan center }\end{array}\right.$

$a\left(h_{m}\right)$ adalah faktor koreksi antena mobile yang nilainya sebagai berikut: $\mathrm{a}\left(h_{m}\right)=3.2\left(\log 11.75 h_{m}\right)^{2}-4.97 \mathrm{~dB}$

dengan :

$L u \quad=$ Path loss rata-rata $(\mathrm{dB})$.

$f=$ Frekuensi $(\mathrm{MHz})$.

$h_{b} \quad=$ Tinggi antena Base station $(\mathrm{m})$.

$h_{m} \quad=$ Tinggi antena Mobile Station $(\mathrm{m})$.

$d \quad=$ Jarak antara MS dan BS (km)[3].

\subsection{Major Quality of Service (QOS) KPI Pada LTE}

A. Reference Signal Received Power

Tabel 1 merupakan mayoritas parameter yang digunakan pada teknologi LTE.

Tabel 1. parameter yang digunakan pada LTE

\begin{tabular}{|l|l|l|l|}
\hline \multicolumn{1}{|c|}{ Parameter } & GSM & UMTS & LTE \\
\hline $\begin{array}{l}\text { Daya (e)NodeB per Tx } \\
\text { (dBm) }\end{array}$ & 43 & 43 & 43 \\
\hline Bandwidth (MHz) & 0,2 & 5 & 20 \\
\hline Jumlah resource Block & N/A & N/A & 100 \\
\hline $\begin{array}{l}\text { Daya BCCH /Daya } \\
\text { CIPCH/Daya RS per } \\
\text { RE }\end{array}$ & 43 & 33 & 15,2 \\
\hline RX lev /RSCP/RSRP & -77 & -87 & -104.8 \\
\hline $\begin{array}{l}\text { Kuat Sinyal RS Signal } \\
\text { yang Diterima dari Ke- } \\
\text { seluruhan Bandwidth }\end{array}$ & & & -81.8 \\
\hline
\end{tabular}

Tabel 2 merupakan contoh range RSRP yang digunakan pada suatu operator [4].

Tabel 2. Reference Signal Received Power pada LTE.

\begin{tabular}{|c|c|}
\hline Nilai & Keterangan \\
\hline$-70 \mathrm{dBm}$ to $-90 \mathrm{dBm}$ & Baik \\
\hline$-91 \mathrm{dBm}$ to $-110 \mathrm{dBm}$ & Normal \\
\hline$-110 \mathrm{dBm}$ to $-130 \mathrm{dBm}$ & Buruk \\
\hline
\end{tabular}




\subsection{Tilting Antena}

Tilting adalah aktivitas pengubahan konfigurasi antena secara fisik untuk memperoleh jangkauan sel yang diinginkan. Tilting antena bertujuan untuk menambah jangkauan antena. Tilting terbagi menjadi dua yaitu mechanical tilting dan electrical tilting.

1. Mechanical tilting adalah mengubah azimuth antenna dan tingkat kemiringan antena secara fisik. Dampak yang dihasilkan oleh mechanical tilting adalah berubahnya luas coverage area secara keseluruhan.

2. Electrical Tilting adalah kegiatan mengubah daya fasa pancar antena dengan cara mengatur parameter kelistrikan pada antena. Berbeda dengan mechanical tilting, perubahan pada electrical tilt hanya akan berdampak pada ukuran main lobe yang dipancarkan oleh antena. Semakin besar nilai electrical maka semakin kecil pula coverage yang diberikan. [5]

\subsection{Lampu Penerangan jalan}

Lampu penerangan jalan merupakan bagian dari bangunan pelengkap jalan yang dapat diletakkan atau dipasang di kiri/kanan jalan dan atau di tengah (di bagian median jalan) yang digunakan untuk menerangi jalan maupun lingkungan di sekitar jalan yang diperlukan termasuk persimpangan jalan, jalan layang, jembatan dan jalan di bawah tanah. Lampu penerangan jalan perkotaan mempunyai fungsi antara lain:

1. Menghasilkan kekontrasan antara obyek dan permukaan jalan.

2. Sebagai alat bantu navigasi pengguna jalan.

3. Meningkatkan keselamatan dan kenyamanan pengguna jalan, khususnya pada malam hari.

4. Mendukung keamanan lingkungan, memberikan keindahan lingkungan jalan[6].

\section{METODE PENELITIAN}

Metode yang digunakan dalam penelitian ini yaitu melakukan klarifikasi ketinggian lampu penerangan jalan, melakukan desain penempatan base station pada lampu penerangan jalan, melakukan perhitungan dan simulasi untuk mengetahui jarak jangkuan antena. Melakukan simulasi dengan lampu penerangan jalan secara keseluruhan, menghapus beberapa titik untuk mengurangi terjadinya overlapping coverage, melakukan tilting antena apabila terjadi blankspot pada wilayah perencanaan. Untuk lebih jelasnya, flowchart Penelitian dapat dilihat pada Gambar 2.

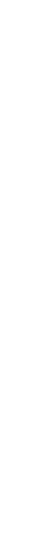

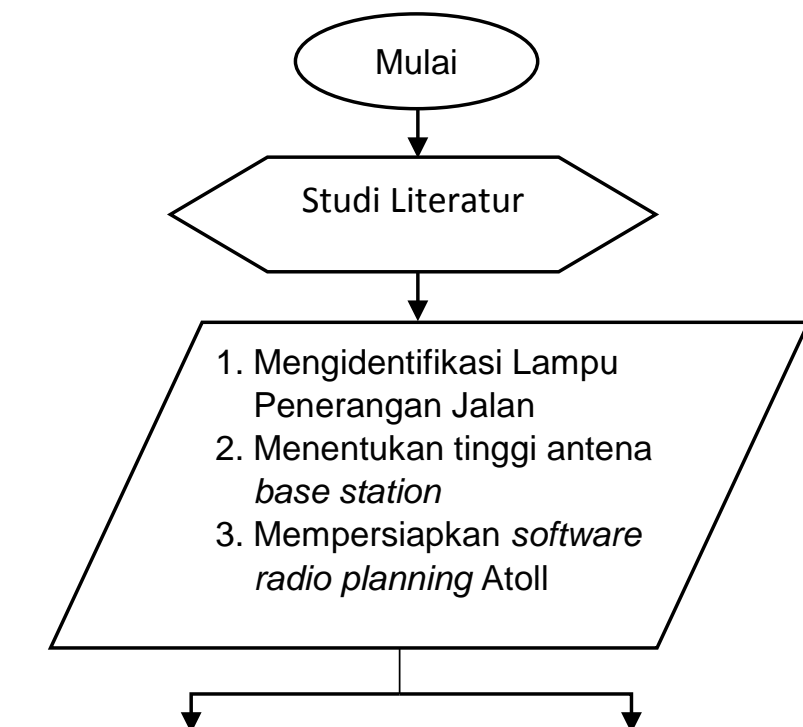

Menghitung jarak jangkuan antena dengan model propagasi cost 231
Melakukan simulasi jarak jangkuan antena dengan ketinggian berbeda

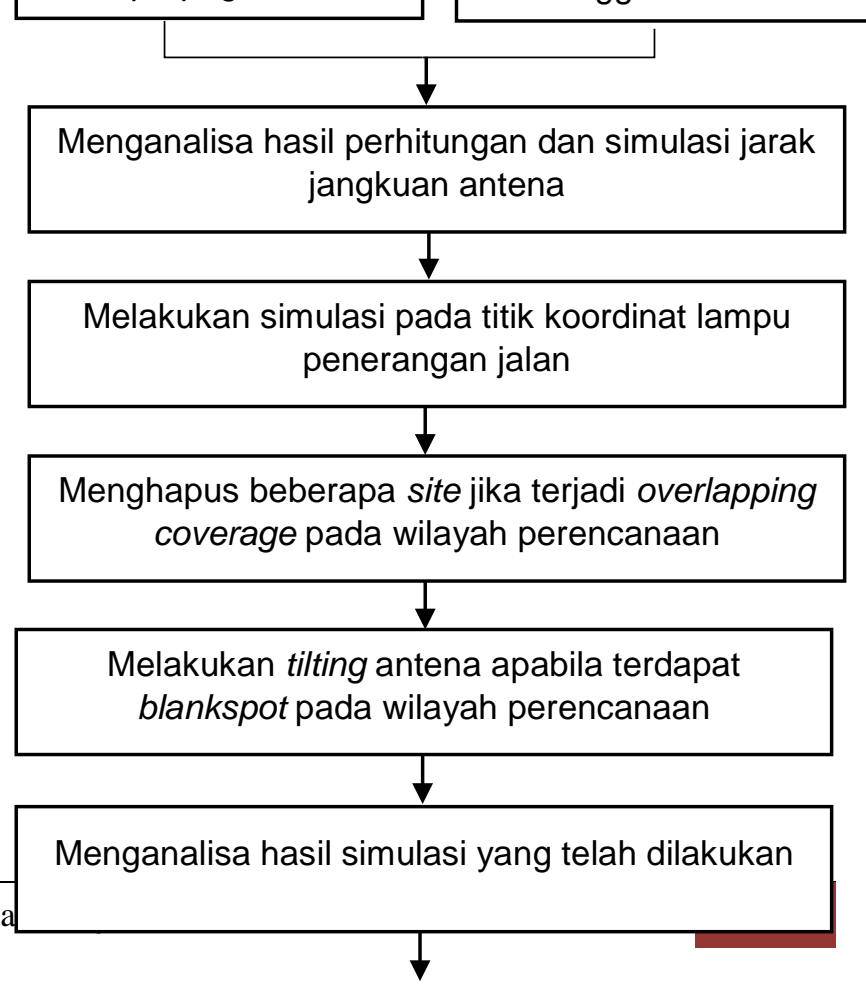




\section{Selesai}

Gambar 2. flowchart Penelitian

\section{HASIL DAN PEMBAHASAN}

\subsection{Hasil Perencanaan}

\subsubsection{Gambaran Lampu Penerangan Jalan}

Lampu penerangan jalan adalah bagian dari bangunan pelengkap jalan yang dapat diletakkan/dipasang di kiri/kanan jalan dan atau di tengah (di bagian median jalan), digunakan untuk menerangi jalan maupun lingkungan di sekitar jalan, termasuk persimpangan jalan (intersection), jalan layang (interchange, overpass, fly over), jembatan dan jalan di bawah tanah. Gambar 3 merupakan gambaran lampu penerangan jalan kota Denpasar.

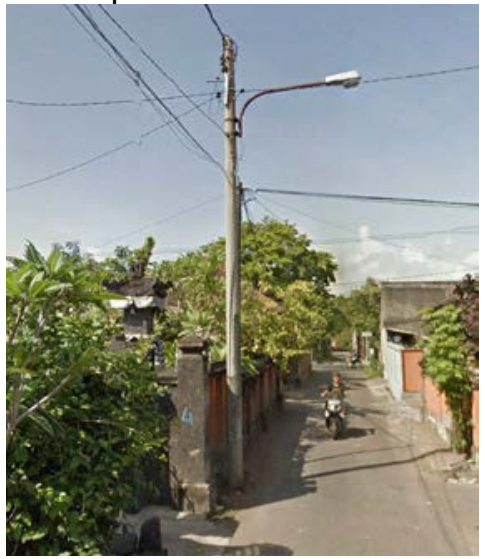

Gambar 3. Lampu Penerangan Jalan wilayah kota Denpasar

\subsubsection{Desain antena microcell pada Lampu Penerangan Jalan}

Setelah mengetahui kondisi lampu penerangan di wilayah kota Denpasar maka langkah berikutnya adalah melakukan desain antena pada lampu penerangan jalan. Desain base staion dilakukan berdasarkan ketinggian lampu penerangan jalan. Desain antena base station dilakukan dengan menambahkan tiang setinggi 3 meter pada tiang lampu penerangan jalan. Penambahan tiang dilakukan sebagai penempatan antena base station pada lampu penerangan jalan. Penempatan antena pada lampu penerangan jalan dapat dilakukan berdasarkan kebutuhan provider, jika tidak memenuhi kriteria akan dilakukan penempatan tiang baru.

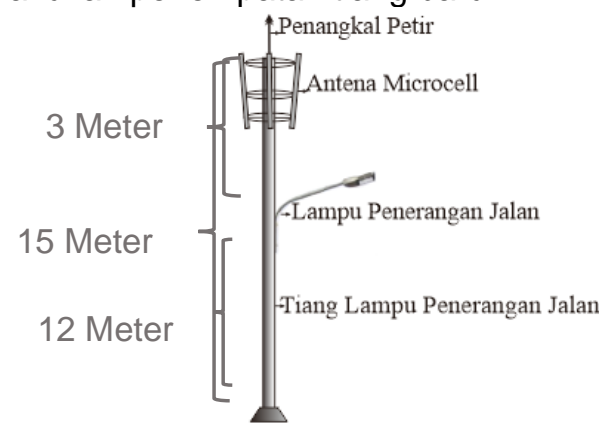

(A)

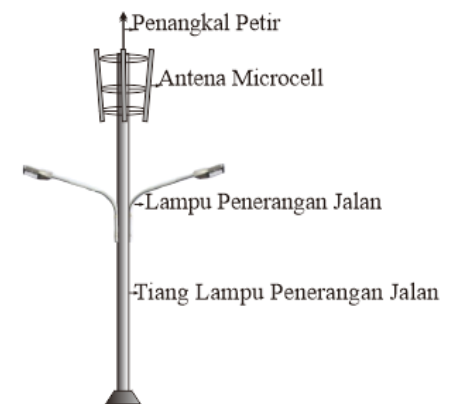

(B)

Gambar 4. Desain Antena pada Lampu Peneranngan Jalan

Gambar 4 merupakan hasil desain antena pada salah satu lampu penerangan jalan. Penambahan desain dila-kukan pada salah satu lampu penerangan jalan dengan tinggi 12 meter dengan menambahkan tiang 3 meter. Sehingga tinggi tiang keseluruhan pada desain lampu penerangan jalan yaitu 15 meter. Penerapan desain antena dibagi menjadi 2 yaitu, desain lampu penerangan jalan di sepanjang jalan trotoar seperti terlihat pada Gambar 3(A) dan desain lampu penerangan jalan di pembatas tengah jalan seperti terlihat pada Gambar 3(B). Tinggi base staion yang digunakan berdasarkan tinggi lampu penerangan jalan yaitu 6 meter, 8 meter, 10 meter, 12 meter, dan 20 meter, sehingga dengan tinggi tersebut cakupan sinyal yang dipancarkan tidak sejauh macrocell yaitu sekitar 900 meter sampai dengan $2 \mathrm{~km}$. 


\subsection{Pembahasan}

Perencanaan jaringan LTE dengan memanfaatkan lampu penerangan jalan sebagai titik base station di wilayah Denpasar dilakukan berdasarkan perhitungan dan simulasi.

\subsubsection{Perhitungan Model Propagasi Cost-231 Hatta}

Model propagasi Cost-231 Hatta terdiri dari beberapa parameter, yaitu path loss ratarata $(L u)$, frekuensi $(f c)$, ketinggian antena $(h t)$, dan ketinggian mobile station ( $h t)$. Berdasarkan persamaan 1, maka perhitungannya adalah sebagai berikut.

$$
\begin{aligned}
L u= & 46.3+33.9 \log f-13.82 \log h_{b}- \\
& a\left(h_{m}\right)+\left(44.9-6.55 \log h_{b}\right) \log d+ \\
& C_{m}
\end{aligned}
$$

$$
\begin{aligned}
139 \mathrm{~dB}= & 46,3+33,9 \log 1800 \mathrm{MHz}-13,82- \\
& \log (23 \mathrm{~m})-3,29 \mathrm{~dB}+(44,9-6,55 \\
& \log (23 \mathrm{~m})) \log \mathrm{d}+0
\end{aligned}
$$$$
139 \mathrm{~dB}=46,3+33,9 \times 3,25-13,82 \times 1,36
$$$$
-3,29 \mathrm{~dB}++(44,9-6,55 \times 1,36)
$$$$
\log d+0
$$

$$
\begin{aligned}
139 \mathrm{~dB} & =134+36 \log \mathrm{d} \\
\log \mathrm{d} & =0.2 \\
\mathrm{~d} & =1,6 \mathrm{~km}
\end{aligned}
$$

Dari hasil perhitungan, maka didapatkan jarak pada model propagasi Cost -231 Hatta pada ketinggian 23 meter adalah 1,6 km.

\subsubsection{Simulasi Perhitungan Jarak Jangkauan Antena dan Throughput pada Software atoll}

Simulasi dilakukan menggunakan software radio planning atoll. Gambar 5 merupakan hasil simulasi jarak jangkuan antena pada ketinggian 23 meter.

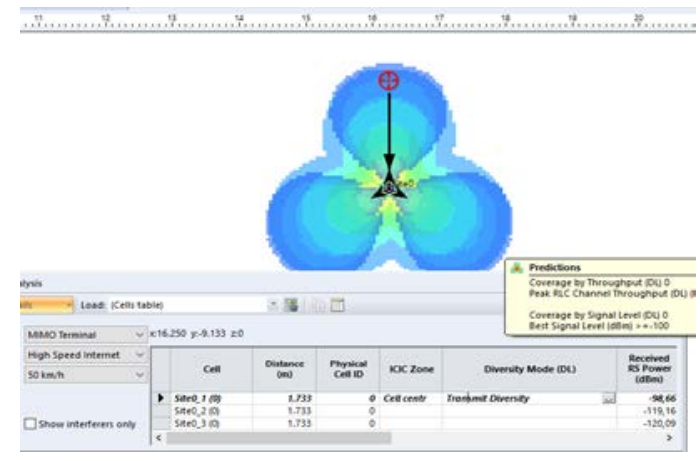

Gambar 5. Hasil Analisis Cakupan Area Pada Tinggi Antena 23 meter.

Pada ketinggian antena 23 meter didapatkan jarak pancar 1,641 Km dengan receiver sensitivity $-95,84 \mathrm{dBm}$. Pada hasil perhitungan yang dilakukan, jarak jangkauan antena yang dihasilkan pada receiver sensitivity $96 \mathrm{dBm}$ adalah 1,6 km. Perbedaan perhitungan dengan simulasi disebabkan terdapat beberapa perbedaan penggunaan parameter pada perhitungan dan simulasi. Pada saat melakukan perhitungan spesifikasi perangkat yang digunakan adalah spesifikasi perangkat 3GPP, sedangkan pada simulasi hanya menggunakan power transmitter, antena gain, cable loss, body loss, receiver noise figure, receiver sensitivity, dan beamwidth. Hal ini dapat menyebabkan terjadinya perbedaan antara hasil perhitungan dengan hasil simulasi. Hasil simulasi jangkauan antenna dan ditunjukkan pada Tabel 3 merupakan hasil simulasi jangkauan antenna dan nilai throughput dengan tinggi yang berbeda.

Tabel 3. Hasil Simulasi Jarak Jangkauan Antena dengan Ketiggian Berbeda.

\begin{tabular}{|l|l|l|l|}
\hline $\begin{array}{l}\text { Tinggi } \\
\text { tiang }\end{array}$ & $\begin{array}{l}\text { Power } \\
\text { Transmitter }\end{array}$ & RSRP & Jarak \\
\hline 23 meter & $43 \mathrm{dBm}$ & $-95,84 \mathrm{dBm}$ & $1,641 \mathrm{~km}$ \\
\hline 15 meter & $43 \mathrm{dBm}$ & $-95,84 \mathrm{dBm}$ & $1,468 \mathrm{~km}$ \\
\hline 13 meter & $43 \mathrm{dBm}$ & $-95,59 \mathrm{dBm}$ & $1,349 \mathrm{~km}$ \\
\hline 11 meter & $43 \mathrm{dBm}$ & $-95,78 \mathrm{dBm}$ & $1,297 \mathrm{~km}$ \\
\hline
\end{tabular}

\subsubsection{Simulasi Perencanaan LTE dengan Menggunakan Titik Lampu Penerangan Jalan Umum Kota Denpasar}


Simulasi Perencanaan LTE menggunakan perencanaan site baru oleh karena itu penempatan site tidak berdasarkan site yang telah ada sebelumnya. Simulasi perencanaan LTE dilakukan dengan menggunakan frekuensi 1800 Mhz. hasil cakupan sinyal yang dihasilkan pada lampu penerangan ditunjukkan pada Gambar 6.

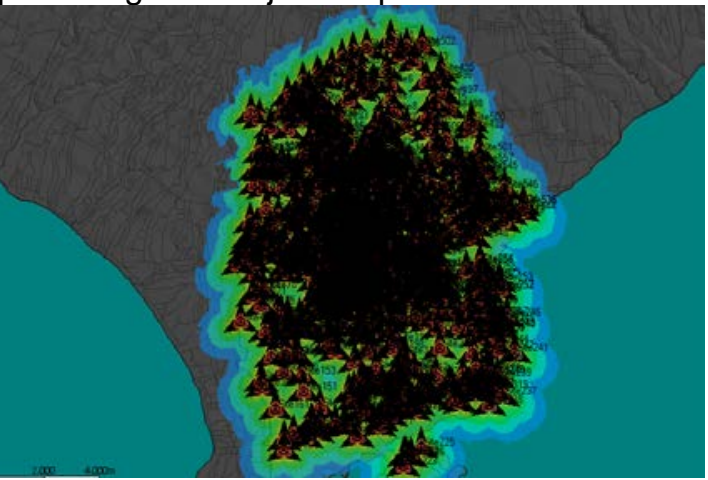

Gambar 6. Hasil Cakupan Area Secara Keseluruhan pada software Atoll.

Pada Gambar 6 terlihat bahwa seluruh wilayah kota Denpasar dapat tercakupi. Setiap site memiliki kuat sinyal yang berbedabeda. Dari simulasi yang dilakukan perlu dilakukan langkah berikutnya untuk menentukan kelayakan simulasi. Simulasi yang dilakukan berikutnya bertujuan untuk mengetahui terjadinya overlapping setiap site. Simulasi lanjutan menghasilkan hasil cakupan sinyal yang dihasilkan ditunjukkan pada Gambar 7.

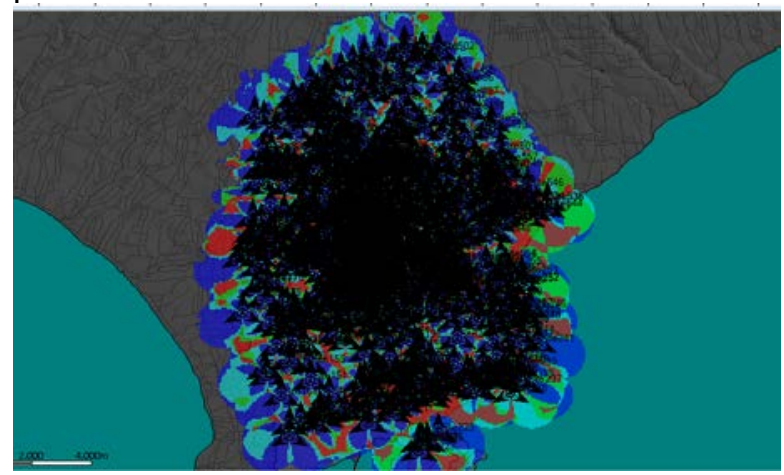

Gambar 7.Hasil overlapping coverage keseluruhan pada software Atoll.

Gambar 7 menunjukkan terjadinya overlapping coverage pada simulasi yang dilakukan, ada beberapa site terjadi overlapping coverage. Dengan kondisi seperti ini maka kualitas sinyal yang diberikan setiap site akan mengalami penurunan karena terjadinya interferensi sinyal. Untuk mengatasi terjadinya overlapping coverage, maka perlu dilakukan tahap berikutnya dengan mengurangi jumlah site agar dapat mencakupi seluruh wilayah perencanaan dengan menggunakan jumlah site yang sedikit.

Hasil pengurangan jumlah site pada daerah overlapping coverage pada simulasi yang telah dilakukan ditunjukkan pada Gambar 8.

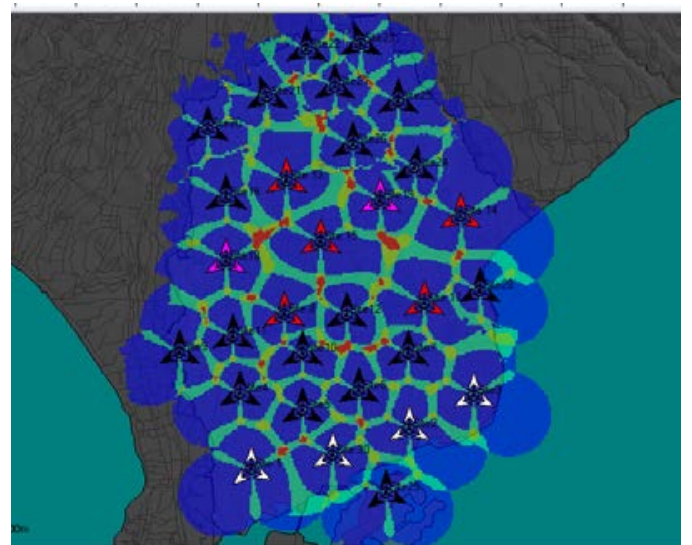

Gambar 8. Hasil Pengurangan Site pada Overlapping Coverage pada Software Atoll.

$\begin{array}{rccc}\text { Gambar } & 8 & \text { merupakan hasil } \\ \text { pengurangan jumlah } & \text { site yang telah }\end{array}$ dilakukan. Pada simulasi yang telah dilakukan, penggunaan tinggi antena dapat diberikan dengan warna yang berbeda. Hal ini bertujuan untuk mempermudah mengetahui tinggi antena yang digunakan. Untuk mengetahui tinggi site pada simulasi tersebut dapat dilihat pada Tabel 4.

Tabel 4. Pembagian Warna Berdasarkan Tinggi Antena.

\begin{tabular}{|l|l|}
\hline Warna site & keterangan \\
\hline & 23 meter \\
\hline & 15 meter \\
\hline & 13 meter \\
\hline & 11 meter \\
\hline
\end{tabular}

Pengurangan jumlah site dilakukan agar dapat mengurangi overlapping coverage pada simulasi yang dilakukan. Dengan pengurangan jumlah site yang dilakukan dapat dikatakan bahwa kota Denpasar telah 
tercakupi secara keseluruhan, sesuai dengan perencanaan yang dilakukan. Namun terdapat beberapa wilayah yang blankspot. Untuk mengetahui wilayah blankspot dapat dilihat pada Gambar 9.

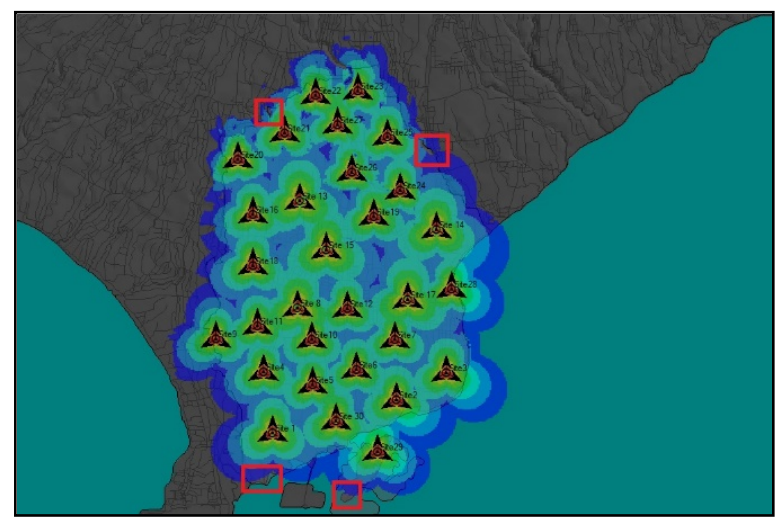

Gambar 9. Lokasi Wilayah Blankspot pada Software Atoll

Gambar 9, pada Gambar kotak merah merupakan daerah blankspot yaitu pada Site 6_2, Site 24_1, Site21_1, Site25_2 dan site 29_3. Karena adanya blankspot maka diperlukan tahapan berikutnya, yaitu mengubah tilt antena agar dapat mencakupi wilayah blankspot. Pada simulasi ini parameter yang diubah adalah sudut kemiringan antena yang semula $0^{\circ}$ menjadi $1^{0}$ hingga $10^{\circ}$.sehingga didapatkan hasil yang ditunukkan pada gambar 10 .

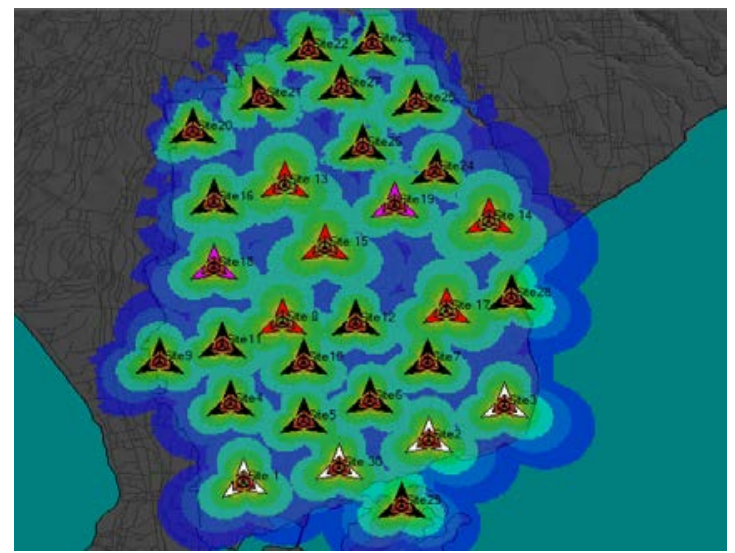

Gambar 10. Hasil Cakupan Area pada Wilayah Blankspot

Gambar 10 merupakan perubahan sudut antena pada daerah blankspot. Terlihat bahwa pada Site 6_2, Site 24_1, Site21_1 dan Site25_2 pada wilayah blankspot sudah dapat tercakupi namun terdapat daerah blankspot seperti Site29_3. Untuk mengetahui luas daerah cakupan yang dilakukan pada simulasi tersebut dapat dilihat pada Gambar 11.

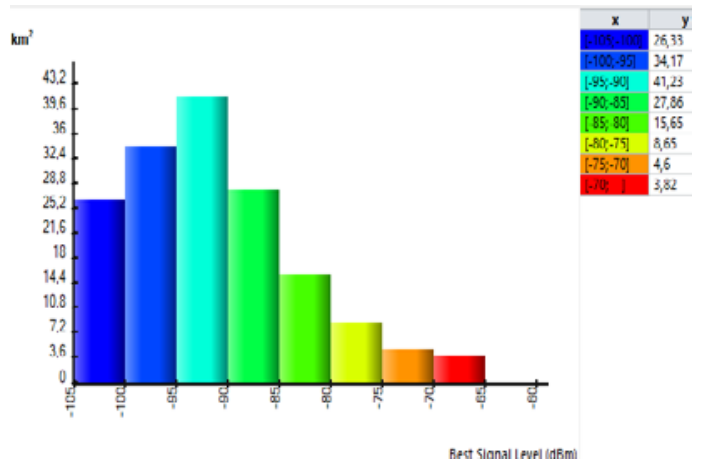

Gambar 11. Hasil Coverage Area Secara Keseluruhan

Pada simulasi yang telah dilakukan cakupan area yang dihasilkan secara keseluruhan yaitu $162,31 \mathrm{~km}^{2}$. Dengan kondisi seperti ini dapat dikatakan bahwa wilayah kota Denpasar sudah dapat tercakupi. Hal ini dikarenakan luas wilayah kota Denpasar yaitu $127,78 \mathrm{~km}^{2}$. Untuk mengetahui apakah benar-benar tercakupi di wilayah kota Denpasar. maka langkah berikutnya yaitu dengan mengimport hasil simulasi ke google earth .

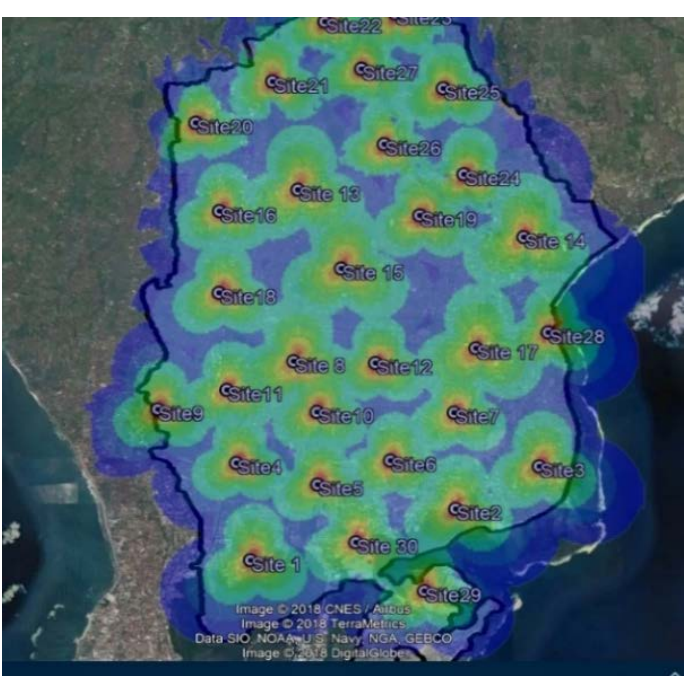

Gambar 12. Hasil Perencanaan Pada Google Earth 
Gambar 12 menunjukkan bahwa wilayah kota Denpasar sudah dapat tercakupi. Dari hasil simulasi yang telah dilakukan jumlah site yang dibutuhkan 30 untuk mencakupi wilayah kota Denpasar, Site ini terdiri dari 5 site dengan tinggi antena 23 meter, 4 site dengan tinggi antena15 meter, 2 site dengan tinggi antena 13 meter serta 21 site dengan tinggi antena 11 meter.

\section{SIMPULAN}

Hasil penelitian ini dapat disimpulkan bahwa jarak jangkauan yang dihasilkan pada ketinggian 11 meter, 13 meter,15 meter, dan 23 meter adalah $1,2 \mathrm{~km}, 1,3 \mathrm{~km}, 1,4 \mathrm{~km}$, dan $1,6 \mathrm{~km}$. Dengan jarak jangkauan yang dihasilkan ini maka jumlah lampu penerangan jalan yang digunakan untuk layanan LTE di wilayah Denpasar adalah 21 site dengan ketinggian 11 meter, 2 site dengan ketinggian 13 meter, 4 site dengan ketinggian 15 meter, dan 5 site dengan ketinggian 23 meter. Jadi total secara keseluruhan adalah 30 site.

Dari hasil penelitian yang telah dilakukan dapat dikatakan kota Denpasar sudah dapat tercakupi, namun terdapat wilayah blankspot. Wilayah blankspot tersebut wilayah pesisir hutan dan tidak adanya penduduk menetap pada wilayah tersebut. Sehingga lampu penerangan jalan tidak terdapat pada wilayah blankspot tersebut.

Penelitian ini dilakukan berdasarkan perencanaan baru. Sehingga penelitian selanjutnya dapat dilakukan berdasarkan lampu penerangan jalan yang sudah ada. Sehingga lampu penerangan jalan digunakan sebagai solusi jika satu wilayah tidak tercakupi layanan LTE.

\section{DAFTAR PUSTAKA}

[1] Bursandy, A., Ziad I., Suroso. 2017. Analisis Kinerja Perbandingan Jaringan 4G Long Term Evolution Bandwidth 10 Mhz dan 15 Mhz dengan Metode Global Frequency Retunning (Tugas Akhir) Sumatera Selatan. Politeknik Negeri Sriwijaya.

[2] Hikmaturokhman, A., Wardhana. L. 2014. 4G Handbook Jakarta selatan :www.nulisbuku.com.
[3] Putra, T.G.A.S. 2015. Analisis Pengaruh Model Propagasi dan Perubahan Antena Terhadap Coverage Area Sistem Long Term Evolution Menggunakan Software Atoll. (Tugas Akhir) Denpasar. Universitas Udayana.

[4] Dewantara.W., Windi, A.W., widiathmoko. 2010. Analisa Pengaruh Down tilt Antena untuk Mengurangi Kegagalan Hadover pada Jaringan Seluler GSM PT. Indosat, Tbk Porweketo (Tugas Akhir) Purbalingga. Universitas Jenderal Soedirman.

[5] Standar Nasinal Indonesia (SNI). 2008 : Spesifikasi Penerangan Jalan di Kawasan Perkotaan.

[6] Dinas Perhubungan Wilayah Kota Denpasar. 2017: Lampu Penerangan Jalan Kota Denpasar 